\title{
A Case of Multiple Hemorrhagic Gastric Ulcers Developed via a Mechanism Similar to Water-Immersion Restraint Stress
}

\author{
Yoshihiro Inoue*, Yasuhisa Fujino, Makoto Onodera, Satoshi Kikuchi, Masayuki Sato, \\ Hisaho Sato, Hironobu Noda, Masahiro Kkojika, Yasushi Suzuki, Shigeatsu Endo \\ Department of Critical Care Medicine, School of Medicine, Iwate Medical University, Morioka-Shi, Japan \\ Email: *yinoue@iwate-med.ac.jp
}

Received 21 September 2015; accepted 24 November 2015; published 27 November 2015

Copyright (C) 2015 by authors and Scientific Research Publishing Inc.

This work is licensed under the Creative Commons Attribution International License (CC BY). http://creativecommons.org/licenses/by/4.0/

(c) (i) Open Access

\begin{abstract}
In rats, water-immersion restraint stress is a model of experimental ulceration. We encountered a case in which multiple hemorrhagic gastric ulcers formed in the stomach in a setting similar to water-immersion restraint stress. The patient was a 54-year-old man who was found wet on a riverbank and transported by ambulance. Because of hypothermia and renal failure, hemodialysis was performed. Tarry stools were noted and endoscopy revealed the presence of multiple hemorrhagic gastric ulcers; thus, hemostasis was performed end oscopically. During the course, pseudo membranous colitis also developed and was ameliorated with vancomycin. Further, the renal failure and gastric ulcers improved, and the patient was discharged from hospital 25 days later. The reason why he survived more than 2 weeks was the hot summer season and he was not soaked in the river water throughout.
\end{abstract}

\section{Keywords}

Water-Immersion Restraint Stress, Acute Gastric Mucosal Legion, Endoscopic Hemostasis

\section{Introduction}

There are many kind of stress causes of experimental ulceration. Water-immersion restraint stress is a famous one of them. In rats, water-immersion restraint stress is a model of experimental ulceration. This is a well-known method involving immersion of limbs in water for a long time to produce the stress response, i.e., ulceration. Stress ulcers are produced spotted or linear ulcers that occur only in the gastric corpus. We encountered a case in

${ }^{*}$ Corresponding author.

How to cite this paper: Inoue, Y., Fujino, Y., Onodera, M., Kikuchi, S., Sato, M., Sato, H., Noda, H., Kkojika, M., Suzuki, Y. and Endo, S. (2015) A Case of Multiple Hemorrhagic Gastric Ulcers Developed via a Mechanism Similar to Water-Immersion Restraint Stress. Open Journal of Clinical Diagnostics, 5, 136-140. http://dx.doi.org/10.4236/ojcd.2015.54022 
which multiple hemorrhagic gastric ulcers formed in the stomach in a setting similar to water-immersion restraint stress.

\section{Case Report}

The subject was a 54-year-old man with a chief complaint of weakness of the entire body and a history of gastric ulcers. On the night of August 29, mistaken as a suspicious person, he was chased by police officers, and he slipped and fell into a river. He returned to the river bank after a while, but both ends of the bridge were perpendicular below the bridge (Figure 1), and he could not reach land from there. He had no means of communication and stayed under the bridge. As the embankment had no horizontal surface but only an inclined surface and the horizontal blocks were soaking in water, it was impossible to keep dry. He coped with hunger and thirst by consuming the water of the river. On September 15, he was discovered by a person fishing at the opposite bank and was transported by ambulance. His physique and nutrition were moderate and his clothes were wet. He was conscious but weak. His blood pressure was 138/68 mmHg, pulse rate 78 beats/min, and rectal temperature $33.4^{\circ} \mathrm{C}$. There was no anemia, jaundice, spontaneous pain, or tenderness.

The results of blood tests at the first visit are shown in Table 1. Because of renal impairment and hyperkalemia, hemodialysis was started at the outpatient clinic. Tarry stools were detected during dialysis, and thus, emergency upper gastrointestinal endoscopy was performed after dialysis. As shown in Figure 2, multiple hemorrhagic gastric ulcers were identified mainly in the gastric body. After endoscopic hemostasis with a heater probe, he was admitted to the hospital. The antibiotic drug administered was sulbactam/ampicillin (SBT/ABPC); however, 3 days later, lower abdominal pain developed. Abdominal computed tomography (CT) (Figure 3) revealed a thick intestinal wall extending from the ascending colon to the transverse colon. Colonoscopy revealed that there was a pseudo membrane extending from the ascending colon to the transverse colon (Figure 4). Pseudo membranous colitis was diagnosed. Vancomycin was orally administered and the symptoms were ameliorated. Seven days later, he started eating meals, and 12 days later, he was withdrawn from dialysis because of an increase in the urine volume. He followed a favorable course thereafter, and upper and lower gastrointestinal endoscopy showed improvement. Therefore, 25 days later, he was discharged from hospital. Examination performed during the course showed negative test results for Helicobacter pylori antibody. At the present time he is followed up in our hospital as outpatient.

\section{Table 1. Laboratory data of the patient on admission.}

\begin{tabular}{|c|c|c|c|}
\hline \multicolumn{2}{|c|}{ Hematology } & \multicolumn{2}{|c|}{ Blood chemistry } \\
\hline WBC & $20,980 / \mu 1$ & $\mathrm{TP}$ & $6.2 \mathrm{~g} / \mathrm{dl}$ \\
\hline $\mathrm{RBC}$ & $422 \times 10^{4} / \mu 1$ & Alb & $3.5 \mathrm{~g} / \mathrm{dl}$ \\
\hline $\mathrm{Hb}$ & $14.8 \mathrm{~g} / \mathrm{dl}$ & BUN & $236.1 \mathrm{mg} / \mathrm{dl}$ \\
\hline $\mathrm{Ht}$ & $44.00 \%$ & Cre & $5.0 \mathrm{mg} / \mathrm{dl}$ \\
\hline \multirow[t]{2}{*}{ Plt } & $25.3 \times 10^{4} / \mu \mathrm{l}$ & $\mathrm{Na}$ & $144 \mathrm{mEq} / \mathrm{l}$ \\
\hline & & K & $6.2 \mathrm{mEq} / \mathrm{l}$ \\
\hline \multicolumn{2}{|c|}{ Arterial blood gas analysis } & $\mathrm{Cl}$ & 98 mFq/l \\
\hline (room air) & & $\mathrm{Ca}$ & $6.2 \mathrm{mg} / \mathrm{dl}$ \\
\hline $\mathrm{pH}$ & 7.41 & AST & $21 \mathrm{IU} / \mathrm{l}$ \\
\hline $\mathrm{pCO}_{2}$ & $29.5 \mathrm{mmHg}$ & ALT & $26 \mathrm{IU} / \mathrm{l}$ \\
\hline $\mathrm{pO}_{2}$ & $140.2 \mathrm{mmHg}$ & T-Bil & $1.2 \mathrm{mg} / \mathrm{dl}$ \\
\hline $\mathrm{HCO}_{3}$ & $18.3 \mathrm{mmol} / \mathrm{l}$ & Amylase & $42 \mathrm{IU} / \mathrm{l}$ \\
\hline \multirow[t]{3}{*}{$\mathrm{BE}$} & $-5.0 \mathrm{mmol} / \mathrm{l}$ & BS & $114 \mathrm{mg} / \mathrm{dl}$ \\
\hline & & CRP & $5.2 \mathrm{mg} / \mathrm{dl}$ \\
\hline & & CPK & $136 \mathrm{IU} / \mathrm{l}$ \\
\hline
\end{tabular}




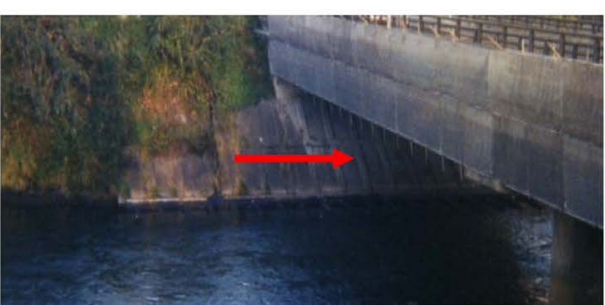

(a)

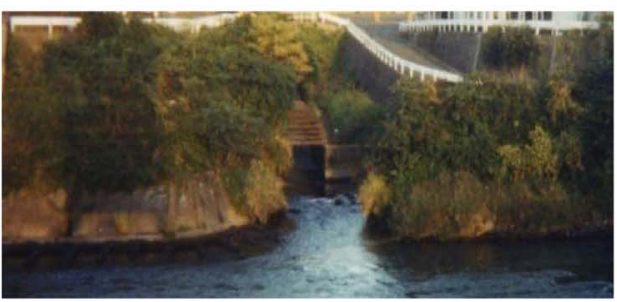

(b)

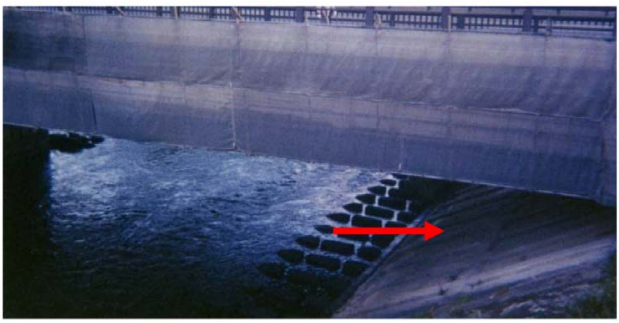

(c)

Figure 1. ((a) and (b)) The photograph around the spot where the patient was found (red arrow). The both end of the bridge were perpendicular below the bridge; (c) The embankment had no horizontal surface.

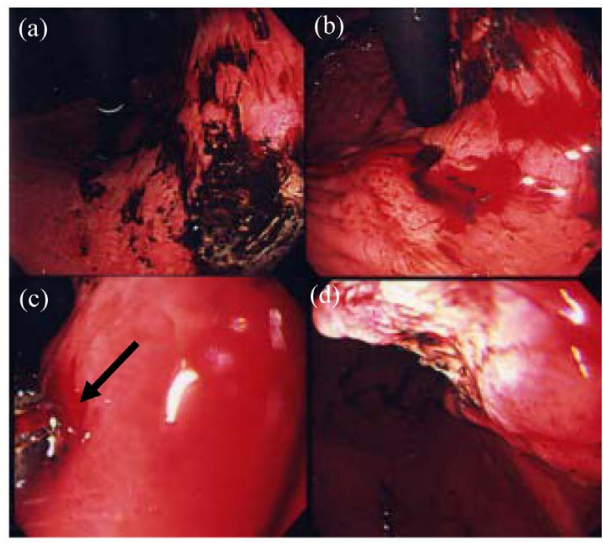

Figure 2. Gastricendoscopy of the patient. ((a) and (b)) Multiple hemorrhagic gastric ulcers were identified in the gastric body; (c) We performed endoscopic hemostasis with heater probe coagulation (arrowhead); (d) There was postcoagulated ulcer.

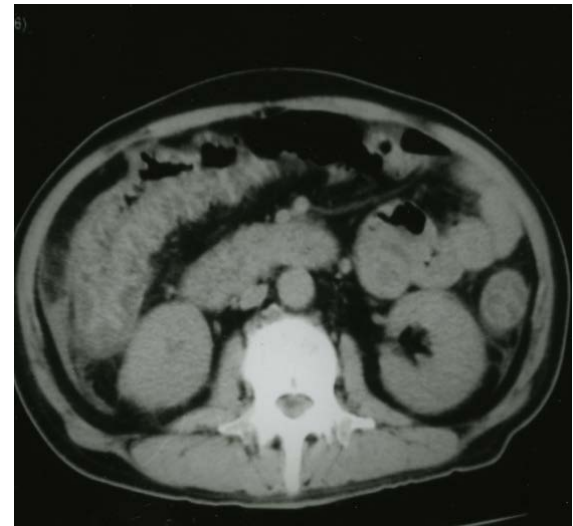

(a)

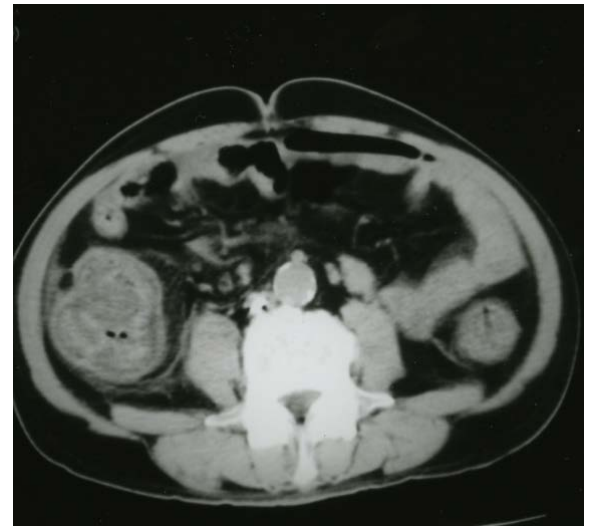

(b)

Figure 3. Abdominal CT film of the patient. We recognized thick intestinal wall of transverse (a) and descending (b) colon. 


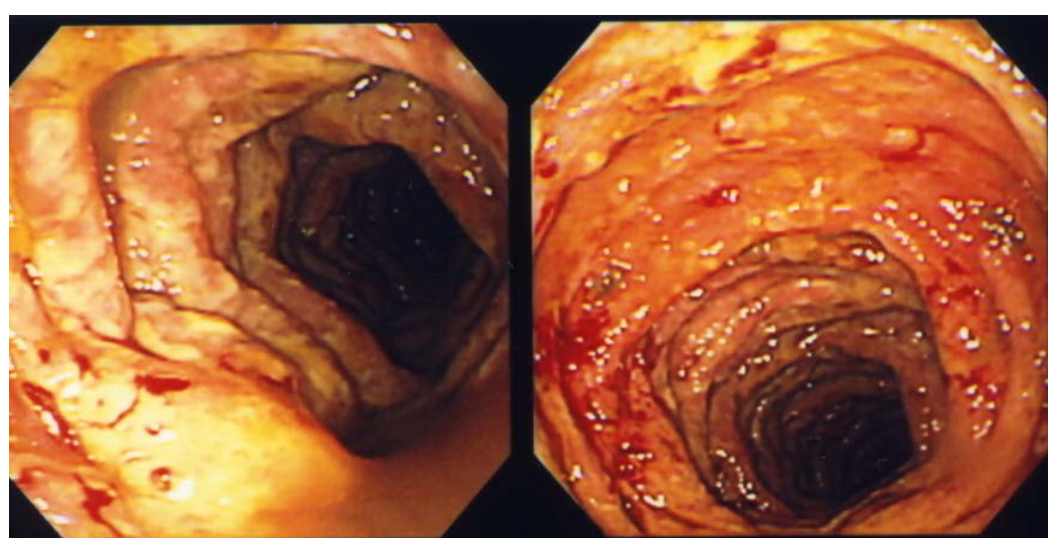

(a)

(b)

Figure 4. Colonoscopy of the patient. We recognized pseudo membranous colitis of ascending (a) and transvers (b) colon.

\section{Discussion}

There are a variety of possible causes for the development of ulcers. The most common cause is H. pylori infection [1]; however, reported cases of acute ulcers show that there are various types of stress (cerebrovascular disorders, thermal burns, infection, etc.) causing ulcers. The following experimental methods have been invented: direct stimulation (using electrical currents or drugs) of the brain (hypothalamus) [2]; restraint [3] [4]; physical stimuli using light, sound, electricity, etc.; and circulatory changes such as blood removal and thermal burns. Of all others, prolonged immersion in water under restraint, also called water-immersion restraint stress, is a method by which many ulcers can be developed in a comparatively short time [5] [6]. In the earlier method of water-immersion restraint stress, limbs of rats were fixed to a plate and immersed in water; however, a disadvantage was the occurrence of necrosis. This led to the development of another method involving placement of rats in small wire netting and immersion of their limbs in water without fixation, thus preventing the disadvantage [7]. In ulceration by water-immersion restraint stress, mucosal damage begins to occur from the second hour, and fairly obvious stress ulceration occurs in 7 hours. Water temperatures of $25^{\circ} \mathrm{C}$ or more reduce the incidence of ulcers, and water temperatures of $20^{\circ} \mathrm{C}$ or less leads to death of the experimental animals; therefore, the recommended water temperature is around $23^{\circ} \mathrm{C}$. Stress ulcers are produced spotted or linear ulcers that occur only in the gastric corpus, and they are histologically "erosion," which fails to penetrate the muscularis mucosa. This is common to ulcers induced by other methods. The reason why ulcers occur in the gastric corpus of the fundic gland region but not in the pyloric gland region is attributed to the difference in the structure of capillaries between the fundic gland and pyloric gland regions. That is to say, the capillaries in the fundic gland region are disposed densely and each of them is thin and long, while the capillaries in the pyloric gland region are distributed roughly and disposed in a dendritic pattern. If blood flow is impaired there, the blood flow in the thin and long capillaries will decrease instantaneously, resulting in a mucous membrane disorder [8]. The ulcers in our case were multiple shallow ulcers that occurred chiefly in the gastric corpus. The riverbank on which the patient stayed put after falling into the river would have been a setting similar to water-immersion restraint stress, and multiple stress ulcers would have formed in the stomach, resulting in bleeding. At that time, the temperature was $28^{\circ} \mathrm{C}$ in the daytime and around $20^{\circ} \mathrm{C}$ at night because of late-summer heat. The subject could have escaped from rain because he was under the bridge; however, he could not escape from the water of the river. Although there is no data regarding the river water temperature, the water temperature measured in the same period several years later was around $18^{\circ} \mathrm{C}$ (Table 2). It is said that, in experiments to produce ulcers by water-immersion restraint stress, animals will die if the water temperature is less than $20^{\circ} \mathrm{C}$. However, in water-immersion restraint stress experiments, rats are always immersed in water as high as the level of the chest. In our case, as the water level is suspected to have been up to the lower limbs, water is assumed to have not conducted heat away from the patient's body all the time, and that aided survival of the patient.

\section{Conclusion}

We encountered a case in which multiple hemorrhagic stress-related ulcers developed under conditions relatively 
Table 2. The liver water temperature and maximum temperature at the same date and maximum temperature at the time.

\begin{tabular}{|c|c|c|c|}
\hline Date & The river water Temperature $\left({ }^{\circ} \mathrm{C}\right)$ & Mavimum Temperature $\left({ }^{\circ} \mathrm{C}\right)$ & Maximum temperature at the time $\left({ }^{\circ} \mathrm{C}\right)$ \\
\hline Aug, 29 & 16.8 & 24.4 & 30.3 \\
\hline Aug. 30 & 18.4 & 27.2 & 32.3 \\
\hline Aug. 31 & 18.4 & 23.9 & 27.3 \\
\hline Sep. 1 & 19 & 28.6 & 30.7 \\
\hline Sep. 2 & 19 & 21.4 & 31.3 \\
\hline Sep. 3 & 17.8 & 23.1 & 31.1 \\
\hline Sep. 4 & 18 & 28 & 31 \\
\hline Sep. 5 & 18.8 & 26.9 & 23.4 \\
\hline Sep. 6 & 17.4 & 26 & 24.7 \\
\hline Sep. 7 & 17.6 & 21.2 & 23.3 \\
\hline Sep. 8 & 17 & 22.6 & 29.3 \\
\hline Sep. 9 & 16.4 & 26.4 & 27 \\
\hline Sep. 10 & 17.4 & 26.9 & 27.7 \\
\hline Sep. 11 & 18 & 24.9 & 28.4 \\
\hline Sep. 12 & 18 & 27.1 & 25.2 \\
\hline Sep. 13 & 17 & 25.5 & 22.3 \\
\hline Sep. 14 & 18.2 & 30.4 & 24.1 \\
\hline Sep. 15 & 19.4 & 24.4 & 21.9 \\
\hline Mean & 17.9 & 25.5 & 27.3 \\
\hline
\end{tabular}

similar to water-immersion restraint stress. It has been assumed that the subject survived more than 2 weeks because of summer heat since he was not soaked in the river water throughout.

\section{Conflict of Interests}

Authors declare no conflict of interests for this article.

\section{References}

[1] Kato, M., Ono, N., Nakagawa, M., et al. (2007) Position of NSAIDs in Causal Factors of Peptic Ulcer. Japanese Journal of Clinical Medicine, 65, 1760-1767.

[2] French, J.D., Porter, R.W., Amerongen, F.K., et al. (1952) Gastrointestinal Hemorrhage and Ulceration Associated with Intracranial Lesions. Surgery, 32, 395-407.

[3] Bonfils, S., Rossi, G., Liefooghe, G., et al. (1958) Les ulcerations gastriques de contrainte du rat blanc. French Journal of Clinical and Biological Research, 3, 703-704.

[4] Roosi, G., Bonfils, S., Liefooghe, G., et al. (1956) Technique nouvelle pour produire des ulcerations gastriques chez le Rat blanc. Comptes Rendus des Seances de la Societe de Biologie, 150, 2124-2126.

[5] Takagi, K., Kasuya, Y. and Watanabe, K. (1964) Studies on the Drugs for Peptic Ulcer. A Reliable Method for Producing Stress ulcer in Rats. Chemical and Pharmaceutical Bulletin, 12, 465-472. http://dx.doi.org/10.1248/cpb.12.465

[6] Watanabe, K. (1966) Some Pharmacological Factors Involved in Formation and Prevention of Stress Ulcer in Rats. Chemical and Pharmaceutical Bulletin, 14, 101-107. http://dx.doi.org/10.1248/cpb.14.101

[7] Okabe, S., Takeuchi, K. and Takagi, K. (1976) Stress Ulcer. In: Umehara, S., Takagi, K., Nagao, F., Matsuo, H., Eds., Experimental Ulcer, Japan Medical Center, Tokyo, 25-33.

[8] Nakamura, N., Sakaguchi, Y. and Hara, S. (1987) Stress Ulcer. In: Matsuo, H., Ed., Newest Digestive Ulcer Survey, R\&D Planning, Tokyo, 354-363. 